\title{
Resilience and Its Association with Depression, Emotional and Behavioural Problems, and Mental Health Service Utilisation among Refugee Adolescents Living in South Australia
}

\author{
Tahereh Ziaian, ${ }^{1}$ Helena de Anstiss, ${ }^{1}$ Georgia Antoniou, ${ }^{2}$ \\ Peter Baghurst, ${ }^{2}$ and Michael Sawyer ${ }^{3}$ \\ ${ }^{1}$ School of Nursing and Midwifery, Division of Health Sciences, University of South Australia, City East Campus, North Terrace, \\ Adelaide, SA 5000, Australia \\ ${ }^{2}$ Public Health Research Unit, Women's and Children's Hospital, Children, Youth and Women's Health Service, 72 King William Road, \\ North Adelaide, SA 5006, Australia \\ ${ }^{3}$ Research and Evaluation Unit, Women's and Children's Hospital, Children, Youth and Women's Health Service, 72 King William Road, \\ North Adelaide, SA 5006, Australia
}

Correspondence should be addressed to Tahereh Ziaian, tahereh.ziaian@unisa.edu.au

Received 10 December 2011; Revised 14 March 2012; Accepted 15 March 2012

Academic Editor: Cherylynn Bassani

Copyright (c) 2012 Tahereh Ziaian et al. This is an open access article distributed under the Creative Commons Attribution License, which permits unrestricted use, distribution, and reproduction in any medium, provided the original work is properly cited.

Background. Despite the frequency of traumatic or stressful events experienced by refugee children and adolescents prior to migration and following resettlement, the majority do not experience mental health problems emphasising the critical nature of resilience. While a host of factors deemed to be protective of mental health in young refugees have been identified, there has been little research exploring the role of resilience as a distinct psychological construct. This study aimed to explore the nature of psychological resilience in refugee adolescents and the relationship between resilience and depression, other emotional and behavioural problems, and mental health service uptake. Method. One hundred and seventy multiethnic refugee adolescents aged 13-17 from South Australia were administered a survey comprising the Connor-Davidson Resilience Scale (CD-RISC), Children's Depression Inventory (CDI), and Strengths and Difficulties Questionnaire (SDQ). Results. Females tended to have higher resilience, as did those adolescents who had been living in Australia longer. Adolescents suffering from depressive symptoms or other emotional or behavioural problems had lower resilience. There was little evidence of an association between resilience scores and exposure to trauma or service utilisation. Discussion. Fostering resilience may be critical to efforts to prevent or reduce mental health problems in refugee adolescents.

\section{Introduction}

Approximately 13,750 refugees arrive in Australia each year, with children and adolescents comprising at least half of this number [1]. Current knowledge suggests that some of these young new arrivals may be at elevated risk of mental health problems associated with a range of traumatic experiences before, during, and after migration [2,3]. For example, two Australian studies on the prevalence of psychiatric disorders in refugee children reported rates of $18 \%$ [4] and 32\% [5] for any psychiatric disorder. The most commonly reported mental health problems in refugee children are posttraumatic stress disorder and depression though studies have found widely varying rates of incidence. For instance, $18 \%$ of Iranian refugee children in Sweden, 25\% of Bosnian children, and $57 \%$ of Cuban refugee children in the US were found to suffer from PTSD [6-8]. Depressive disorders, including major depression, were reported among $17 \%$ of Bosnian adolescents [8] and 12.9\% Cambodian children exiled in the US ([9]; see also, [10]); while $11.5 \%$ Tibetan refugee children in India were also diagnosed as suffering from both PTSD and major depression [11]. A systematic review combining 
data from five studies with 260 refugee children from Bosnia, Central America, Iran, Kurdistan, and Rwanda, and residing in Canada, Sweden, and the US, found a mean rate of $11 \%$ for PTSD [12]. A dose-effect relationship has also been indicated with increasing exposure to traumatic experiences predicting more PTSD symptoms (e.g., $[6,13])$. A recent Australian study demonstrated a rate of $7.2 \%$ for depression in refugee children and adolescents [14].

Although most young refugees exposed to trauma do not develop mental health problems $[15,16]$, resilience and coping are largely neglected in refugee research, theory, and practice [17-19]. Resilience is broadly defined as the ability of a person to successfully adapt to or recover from stressful or traumatic experiences [20]. For example, it is a schoolaged child's ability to make friends, engage in academic pursuits, be guided by primary caregivers, and engage in other behaviours acceptable in his or her society, as well as, be resistant to psychological illness, despite experiencing significant adversity (e.g., war, political oppression, poverty, and child abuse). Although initially, resilience theory focused on personal attributes such as self-esteem, self-efficacy, and hardiness [21], resilience is currently recognised as a multidimensional construct including personal characteristics and skills (e.g., active problem solving) as well as external protective factors such as a supportive family and social environment [22]. It is also conceptualised as a dynamic process that fluctuates according to age, gender, individual circumstance and developmental, historical, and cultural context ([23]; see also [20]).

Although increasing exposure to traumatic experiences has been related to higher levels of psychiatric symptoms in both young and adult refugees, a number of protective/risk factors have been found to impact on their psychological well being. For instance, increased well being and reduced psychological problems in their mothers as assessed at a clinical interview and positive peer relationships (having one or more peers to play with) predicted better well being and social adaptation in refugee children, while physiological, psychological, or developmental vulnerabilities prior to the traumatic event predicted slower recovery from posttraumatic symptoms ([24], see also [25, 26]). Long-time exposure to moderate stressors in refugee camps subsequent to the traumatising events [8] and relative young age at the time of atrocities ([27]; see also $[28,29]$ were related to relative low levels of posttraumatic symptoms. Other protective factors included religious beliefs and practices, which were relatively accessible and afforded a sense of continuity, comfort, and meaning in life ([30] see also [11, 31]), and psychosocial training on nonviolent communication, cooperation, and tolerance [32].

Religious beliefs and practices, supportive family, and community relationships protected against mental health problems and promoted adaptation in adolescent refugees in Australia [33]; while intergenerational conflict between parents struggling to maintain cultural values, gender roles, and traditional forms of discipline and children asserting their freedom and rights and striving to acculturate was a potential risk factor (e.g., $[34,35])$. In the present study with young Australian refugees, resilience (as measured by the CD-RISC scale; [23]) primarily encompasses personal characteristics and skills (sense of personal competence and active problem solving) but does include some protective factors such as social relationships and religious faith.

However, despite this exploration of various factors deemed to be protective of mental health, there has been no systematic attempt to explore the nature and predictors of resilience as a distinct psychological construct in young refugees in the literature to date. This may be critical as research has found that poor resilience predicted the development of psychological symptoms such as depression and anxiety [36], moderated the relationship between childhood adversity and psychiatric sequelae [37], or was a strong predictor of positive affect which in turn predicted depression and, to a lesser extent, anxiety [38]. Recent cross-sectional research with Norwegian adolescents has revealed a strong association between diminished resilience and psychological symptoms such as depression and anxiety $[22,39]$. Thus, the psychological construct of resilience may be a critical element of any interventions to alleviate psychological symptomatology. However, the nature of resilience as a distinct psychological construct has yet to be explored in young refugees. This study therefore aimed to explore the nature and predictors of psychological resilience in refugee adolescents and the association between this resilience and depression, emotional, and behavioural problems and mental health service utilisation.

\section{Method}

2.1. Participants. Participants included 170 refugee adolescents aged 13-17 from the former Republics of Yugoslavia (Bosnia and Serbia) $(N=35,20.59 \%)$, the Middle East and South Asia (Iran, Iraq and Afghanistan) $(N=82,48.24 \%)$, and Northern and Western Africa (Sudan and Liberia) $(N=53,31.18 \%)$ who had migrated, or whose parents had migrated, to Australia between June 1996 and June 2007. This timeframe was used because detailed settlement data only became available in 1996 and these countries were selected because they represented the top refugee source countries at the time. The languages spoken by the participants included Bosnian, Serbian (former Yugoslavia), Arabic, Persian (Middle East and South Asia), Dinka (Sudan), and English (Liberia).

As there was no complete sampling frame from which to draw a random sample, convenience and snowball sampling were used to recruit the participants. The study was widely promoted to the target communities through refugee settlement agencies, schools, community groups, and ethnic media. The data were collected by 20 trained bilingual lay interviewers from the same or similar ethnic backgrounds as participants.

2.2. Instruments. Sociodemographic variables such as age, gender, and ethnicity were assessed using a questionnaire developed by the investigators. Resilience was assessed using the Connor-Davidson Resilience Scale (CD-RISC; [23]) which was translated into the target languages by 
an accredited professional translator and back-translated by an independent bilingual professional from each of the population groups. Participants were given the choice of choosing either the English or the translated version. The CD-RISC is a self-report measure comprising 25 items, with each rated on a 5-point scale as follows: $0=$ not at all true, $1=$ rarely true, $2=$ sometimes true, $3=$ often true, and $4=$ true nearly all of the time. The CD-RISC yields a total resilience score from 0-100, with higher scores reflecting greater resilience.

Factor analysis has demonstrated a five-factor structure as follows: factor 1 relates to personal competence, tenacity, and high standards and is comprised of 8 items including "I believe I can achieve my goals, even if there are obstacles"; factor 2 relates to trust in one's instincts, tolerance of negative affect, and resolve in the face of stress and is comprised of 7 items including "I prefer to take the lead in solving problems, rather than letting others make all the decisions"; factor 3 relates to acceptance of change and feelings of security in relationships and is comprised of 5 items including "I can deal with whatever comes my way"; factor 4 relates to perceived control and is comprised of 3 items including "I have a strong sense of purpose in life"; and factor 5 relates to spiritual beliefs and is comprised of 2 items including "when there are no clear solutions to my problems, sometimes fate or God can help" [23].

The CD-RISC has good internal consistency and testretest reliability, correlates well with measures of stress and hardiness, and differentiates well between community and clinical populations [23]. Increases in resilience measured with the CD-RISC are strongly associated with clinical improvements in psychiatric patients and reflect global improvements in general functioning [23]. The CD-RISC has been used in various cross-cultural studies with population groups from China [40], Korea [41], Turkey [42], Iran [43], Pakistan [44], Russia [45], and South Africa [46]. It has also been used in adolescents from culturally diverse backgrounds $[40,45,46]$.

Depressive symptomatology was assessed using the adolescent version of the Children's Depression Inventory (CDI; [47]). This version of the CDI consist of 27 items and provides a total score along with five subscale scores corresponding with the components of negative mood, interpersonal difficulties, negative self-esteem, ineffectiveness, and anhedonia. The recommended cut-off for determining clinical depression was a total score of 20 . The CDI has been used in studies comprising participants from a diverse range of cultural and linguistic backgrounds [48-51].

Other emotional and behavioural problems were measured using the Strengths and Difficulties Questionnaire (SDQ), a widely used questionnaire designed to identify the presence of emotional and behavioural difficulties in children and adolescents [52]. The validity and reliability of the SDQ has been confirmed in research with culturally diverse populations [53-55] and has been utilised in numerous studies with culturally and linguistically diverse children and adolescents [56-60]. The self-rated SDQ gives rise to a total score and 5 subscales labelled emotional symptoms, conduct problems, hyperactivity, peer problems, and prosocial behaviour as well as an impact score. Scores are classified as normal if they fall between 0 and 15, borderline if between 16 and 19, and abnormal if between 20 and 40 . Higher scores on all scales except the prosocial behaviour scale indicate greater difficulties.

The Migration and Settlement Questionnaire (MASQ; Minas \& Klimidis, unpublished) covered various sociodemographic and settlement information including satisfaction with the Australian sociocultural environment, English language proficiency, and premigration rural/urban origin. Additionally, the instrument included a checklist of 24 traumatic events possibly experienced prior to migration, for example, murder of stranger or strangers, witnessing someone being badly injured or killed, and sustaining a serious injury. Responses to this 24-item checklist were used to assess "exposure to traumatic event." Service utilisation was assessed using questions developed for the Child and Adolescent Component of the Australian National Survey of Mental Health and Wellbeing $[61,62]$. These questions assess the six-month history of utilisation of various mental health or support services in schools, health and community services, outpatient hospital-based services, and various other formal service settings. The Survey was completed by the adolescents and one of their parents.

The CDI, SDQ, MASQ and the Australian National Survey were also translated in the Serbian, Bosnian, Arabic, Persian, and Dinka languages using a similar procedure to that followed in translating the CD-RISC (aforementioned).

2.3. Statistical Analysis. Intercooled Stata 10.1 for Windows was used to perform data analysis. Descriptive statistics were used to describe the demographic features of the study populations and their resilience scores. As the total scores and factor scores were significantly skewed, nonparametric tests including Spearman's rho and the Kruskal-Wallis test were employed to test associations and differences between sociodemographic variables and resilience scores.

2.4. Ethical Considerations. This study was approved by the ethics committees of the University of South Australia, the Women's and Children's Hospital, and the South Australian Department of Education and Children's Services.

\section{Results}

The total sample comprised 170 adolescents, $86(50.6 \%)$ of whom were male. The median age of the sample was 15.56 years (Range 12.25 to $18.16, N=166$ ). The total resilience scores ranged from 0 to 98 , with a median total score of 65.5 $(\mathrm{IQR}=28(77-49))$. Total and factor subscale scores were analysed with respect to a number of social, demographic, psychological, and behavioural factors as illustrated in Table 1. Females were found to have significantly higher resilience for total $\left(\chi^{2}=14.37, P<0.001\right)$ factor $1\left(\chi^{2}=13.62, P<\right.$ $0.001)$, factor $2\left(\chi^{2}=9.20, P=0.002\right)$, factor $3\left(\chi^{2}=7.85\right.$, $P=0.005)$, and factor $4\left(\chi^{2}=16.85, P<0.001\right)$ scores, and also exhibited a strong trend towards higher factor $5\left(\chi^{2}=\right.$ $3.80, P=0.051)$ scores. No significant correlation was found 


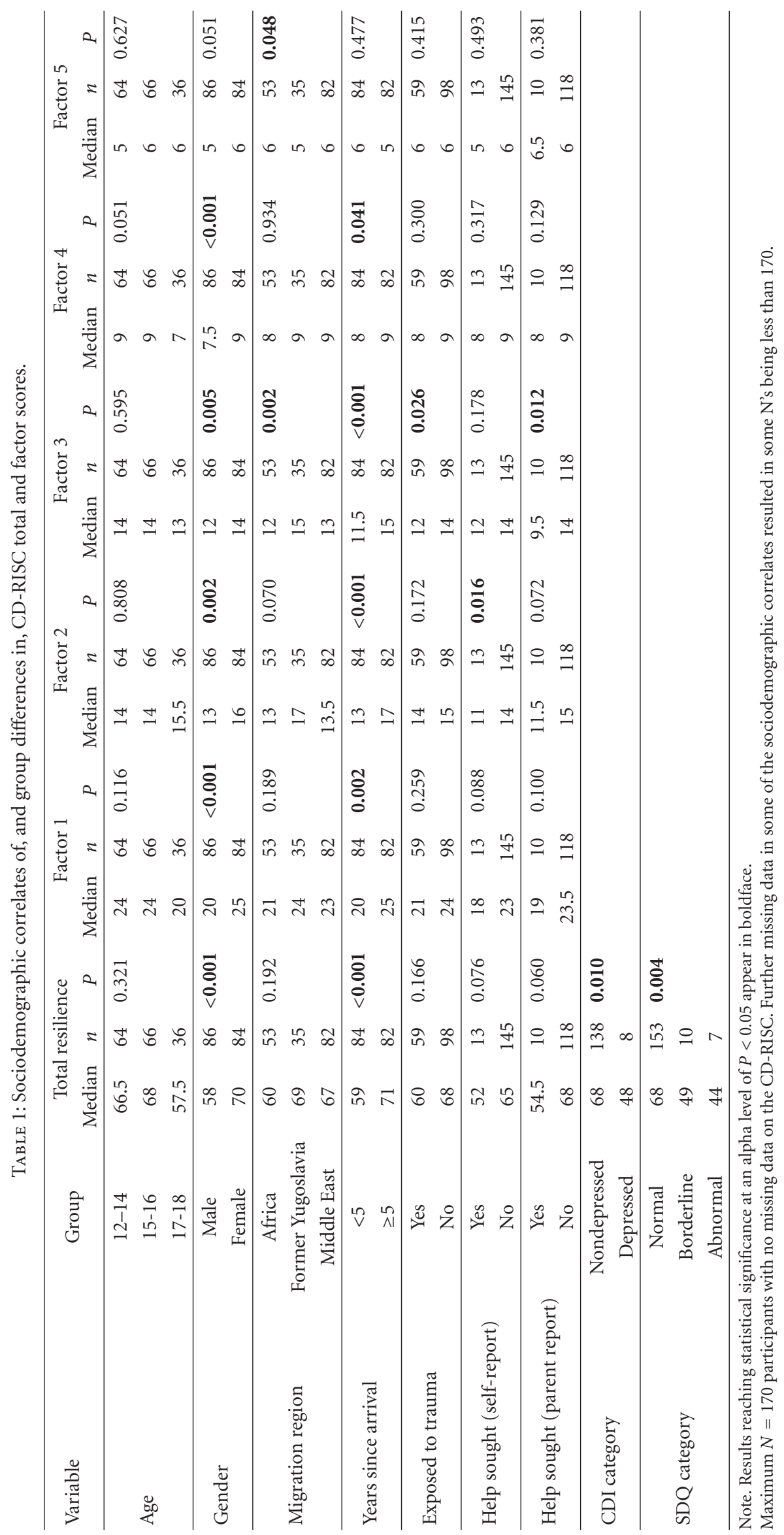


between age and resilience for total $\left(r_{s}=-0.07, P=0.41\right)$, factor $1\left(r_{s}=-0.12, P=0.11\right)$, factor $2\left(r_{s}=0.04, P=0.64\right)$, factor $3\left(r_{s}=-0.09, P=0.26\right)$, factor $4\left(r_{s}=-0.11, P=\right.$ $0.15)$, or factor $5\left(r_{s}=0.001, P=0.99\right)$ scores.

No significant difference was found between migration regions with regards to total $\left(\chi^{2}=3.30, P=0.19\right)$, factor 1 $\left(\chi^{2}=3.33, P=0.19\right)$, factor $2\left(\chi^{2}=5.33, P=0.07\right)$, or factor $4\left(\chi^{2}=0.14, P=0.93\right)$ scores, but there was a significant difference for factor $3\left(\chi^{2}=12.24, P=0.002\right)$ scores, with former Yugoslavians scoring the highest ( median $=15)$, followed by Middle Easterners (median = 13) and Africans (median $=12)$. A significant difference was also found for factor 5 scores $\left(\chi^{2}=6.09, P=0.047\right)$, with Middle Easterners scoring the highest (median $=6$ ), followed by Africans $($ median $=6)$ and former Yugoslavians ( median $=5)$. A significant positive correlation was found between length of time in Australia and total $\left(r_{s}=0.25, P=0.001\right)$, factor $1\left(r_{s}=0.22, P=0.004\right)$, factor $2\left(r_{s}=0.28, P<0.001\right)$, and factor $3\left(r_{s}=0.32, P<0.001\right)$ scores but not factor 4 $\left(r_{s}=0.15, P=0.06\right)$ or factor $5\left(r_{s}=-0.11, P=0.14\right)$ scores. Adolescents within the first five years of resettlement had significantly lower resilience scores than those who had been in Australia for five years or longer on total scale $\left(\chi^{2}=\right.$ 12.29, $P<0.001)$, factor $1\left(\chi^{2}=9.87, P=0.002\right)$, factor 2 $\left(\chi^{2}=14.49, P<0.001\right)$, factor $3\left(\chi^{2}=16.59, P<0.001\right)$, and factor $4\left(\chi^{2}=4.19, P=0.04\right)$, but not factor $5\left(\chi^{2}=0.51\right.$, $P=0.48)$ scores.

While no difference was found between adolescents exposed to trauma and those not exposed on total $\left(\chi^{2}=1.92\right.$, $P=0.17)$, factor $1\left(\chi^{2}=1.27, P=0.26\right)$, factor $2\left(\chi^{2}=1.86\right.$, $P=0.17)$, factor $4\left(\chi^{2}=1.12, P=0.29\right)$, or factor $5\left(\chi^{2}=\right.$ $0.66, P=0.42)$ scores, those exposed to trauma had significantly lower factor $3\left(\chi^{2}=4.97, P=0.03\right)$ scores. No significant correlation was observed between the number of traumatic events experienced and resilience scores for the total subscale $\left(r_{s}=0.04, P=0.74\right)$, factor $1\left(r_{s}=0.11, P=\right.$ $0.40)$, factor $2\left(r_{s}=-0.02, P=0.90\right)$, factor $3\left(r_{s}=0.19, P=\right.$ $0.14)$, factor $4\left(r_{s}=0.13, P=0.34\right)$, or factor $5\left(r_{s}=0.19\right.$, $P=0.15)$.

Total resilience scores were significantly negatively correlated with total CDI $\left(r_{s}=-0.37, P<0.001\right)$ and total SDQ $\left(r_{s}=-0.39, P<0.001\right)$ scores. Adolescents in the "depressed" diagnostic category of the CDI had lower total resilience scores (median $=48$ ) than those who were not depressed $($ median $=68)\left(\chi^{2}=6.70, P=0.01\right)$. Similarly, adolescents in the "borderline" (median = 49) and "abnormal" (median $=44$ ) diagnostic categories of the SDQ had lower resilience scores than those in the "normal" (median $=68)$ category $\left(\chi^{2}=10.89, P=0.004\right)$. Adolescents who sought mental health care had significantly lower factor 2 $\left(\chi^{2}=5.79, P=0.02\right)$ scores $($ median $=11$ versus median $=$ $14)$, and also exhibited a trend towards lower total $\left(\chi^{2}=3.15\right.$, $P=0.08)($ median $=52$ versus 65$)$ and factor $1\left(\chi^{2}=2.90\right.$, $P=0.09)($ median $=18$ versus 23$)$ scores. No observable difference was found with respect to factor $3\left(\chi^{2}=1.82, P=\right.$ $0.18)$, factor $4\left(\chi^{2}=1.00, P=0.32\right)$, or factor $5\left(\chi^{2}=0.47\right.$, $P=0.49)$ scores.

Multiple linear regression analysis, to determine possible predictors of total CD-RISC score, was complicated by the significant correlations existing between each of the SDQ subscales and each of the CDI subscales and also between the total CDI and total SDQ scores. At the univariable level, both the CDI and SDQ total scores as well as each of their subscale scores were significantly associated with the total CD-RISC score. All associations were negative except for a highly significant positive association of the prosocial behaviour score from the SDQ with resilience. In the multivariable model, the CD-RISC scores of females were significantly higher compared to males; the CD-RISC scores of those who had been in Australia for 5 years or more were significantly higher compared to those who had been in Australia for less than 5 years; and the prosocial behaviour score was persistently significant irrespective of other SDQ or CDI scores included in the model.

\section{Discussion}

Our investigation of resilience in refugee adolescents found a mean total score of $62.2(S D=20.4)$, which is lower than that found by Connor and Davidson [23], in the general population $(M=80.4, S D=12.8)$, primary care patients $(M=$ $71.8, S D=18.4)$, and psychiatric outpatients $(M=68.0$, $S D=15.3)$. This score was, however, comparable to that found in generalised anxiety disordered patients $(M=62.4$, $S D=10.7)$ and higher than that found in PTSD patients $(M=47.8, S D=19.5)$ [23]. While further research is needed to compare refugee resilience with that of matched population controls, our findings suggest refugee adolescents may have diminished resilience.

Another important finding was that adolescents who indicated higher levels of resilience had lesser depressive symptomatology and emotional/behavioural problems as assessed by the CDI and SDQ total scores, as well as scores on the CDI subscales (negative mood, interpersonal difficulties, negative self-esteem, ineffectiveness, and anhedonia) and SDQ subscales of emotional and conduct problems, and hyperactivity and peer problems except prosocial behaviour, which was positively related to resilience. This may indicate that resilience protects young refugees against the future onset of mental health and/or that mental health problems have an adverse effect on resilience and coping. Research with nonrefugee adolescents has found that higher resilience including external protective factors such as family cohesion and support from outside the family, predicted lower levels of depression, anxiety, and obsessive-compulsive symptoms $[22,39]$. Though the present study is unable to conclude about the directionality of the associations found between resilience and mental health and behaviour problems, it is likely that the use of more sophisticated research designs as well as instruments that emphasise more on the family and social domains of resilience may enable future researchers to identify resilience as a predictor of mental illness in young refugees. Additionally, it appears that resilient people are also motivated to engage in prosocial behaviours or that helping others facilitates resilience. Future research can investigate the directionality of this relationship, which in turn could aid in the design of effective interventions to enhance resilience and thereby, mental well being. 
A gender difference was demonstrated in total and subscale scores, with females demonstrating greater resilience across all scales. Lower resilience among male adolescents may indicate an increased risk of mental health problems, which is supported by our broader investigation which found that males scored higher on the CDI [14], while females scored higher on the prosocial behaviour subscale of the SDQ [63]. While we found no significant ethnic differences in total resilience scores, ethnic differences were found in some subscale scores, for example, former Yugoslavians reported greater resilience associated with acceptance of change and security in relationships (factor 3), while Middle Easterners and Africans reported greater resilience associated with religious beliefs (factor 5).

A relationship was also found between length of time in Australia and total resilience and subscale scores, with adolescents in the " 5 years or more" group reporting higher total and factors 1, 2, 3, and 4 scores than those in the "less than 5 years" group. This may suggest that resilience increases with adaption and acculturation to Australian society and culture and with the duration of time since experiencing premigratory traumatic events, or a combination of both. Although time since the experience of traumatic events was not specifically assessed in the present study, sociodemographic data indicate that a substantial proportion of children were not exposed to, or could not remember, experiencing traumatic events, but instead were exposed to stressors of a lower intensity during prolonged displacement and/or in Australia (see [8]). For these children at least, adaptation and acculturation to Australian society and culture appear to be associated with greater resilience. Additionally, adaptation and acculturation of their parents or primary caregivers as well as improvement in socio-economic conditions whilst in Australia (e.g., [64]) could also have impacted upon aspects of the children's resilience.

With the exception of lower factor 3 scores among adolescents exposed to trauma, no significant relationship was found between trauma and resilience. This is supported by a study which found no relationship between childhood trauma and CD-RISC scores in substance-dependent adults [65]. Our finding suggests that exposure to trauma does not necessarily reduce overall resilience in refugee adolescents, although it may affect their ability to successfully accept change and feel secure in relationships. We found that those who self-reported seeking help from formal services, or those whose parents reported their child seeking help, had significantly lower factor 2 (tolerate negative effect and resolve in the face of stress) and factor 3 (accepting change and security in relationships) resilience scores, respectively, and exhibited a strong trend towards lower total and factor 1 (personal competence, tenacity, and high standards) scores for adolescent reports and lower total and factor 2 scores for parent reports. However, due to the low numbers of self- and parent-reported help seekers in the sample, it is likely that the failure to reach statistical significance in the analyses is the result of a type 2 error. Lower resilience among adolescents who accessed mental health care is to be expected as presumably those utilising services are in need of them due to limited resilience. This is supported by the finding of lower resilience scores in psychiatric patients compared to community controls in Connor and Davidson's original study [23].

\section{Limitations}

There are a number of limitations to the present study. Firstly, the instruments utilised in this study have not been validated in young refugees from the cultural backgrounds investigated and this limits the confidence in the validity of the findings. However, the instruments have been used in research with children and adolescents from a wide range of countries, cultures, and languages. A second limitation is the recruitment strategy of convenience and snowball sampling which may result in sampling bias and, therefore, limit the generalisability of our findings. However, the large and ethnically diverse sample obtained was comparable according to sociodemographic characteristics with the ethnic populations from which they were drawn when matched against current Australian Bureau of Statistics migration data. Thirdly, not including a control group does not allow the comparison of the results with that of nonrefugee adolescents of both mainstream and culturally diverse backgrounds.

Several limitations regarding the use of CD-RISC as the sole measure of resilience are worth noting. As aforementioned, CD-RISC indicates adequate psychometric properties, reflects the diversity of the resilience construct to some extent, and is a promising measure of resilience in normal and clinical populations [23]. Nonetheless, it does not wholly capture the heterogeneity (personal, family, and social resources; e.g., [22]) or the dynamic processes underlying the resilience construct as it is currently conceptualised. For instance, a refugee child may excel academically at school while having serious conflict at home with his or her parents; and/or the child's resilience level may vary at different stages of development (e.g., younger versus older adolescence); these changes have not been considered. Conversely, some researchers have suggested narrowing its focus and refining the definition of resilience that it captures on the basis that some factors (e.g., spirituality) appear to be less relevant to resilience (e.g., [37]), though in the present study spiritual beliefs were more relevant to some cultural groups (e.g., the Middle Eastern and African adolescents) than to others. Additionally, CD-RISC is based on subjective self-reports of participants and hence subject to the limitations of other self-measurements (e.g., social desirability and demand characteristics). Nonvalidation through objective measures, such as biological and physiological markers or independent coding of reported behaviours by experts, is a limitation of the CD-RISC as well as the present study that has relied solely on the resilience construct captured by the instrument (e.g., $[20,23,37])$.

\section{Implications}

The key findings in this study were the low resilience scores found in this heterogeneous sample of young refugees 
and the significant relationships demonstrated between decreased resilience and mental health and behavioural problems, though no predictions could be made regarding the direction of these associations. If the level of resilience is hypothesised to predict mental health, then young refugees who appear to be lower on resilience may be at greater risk of developing psychopathology than their counterparts in mainstream society as well as within their own communities. Future research is needed to appropriately compare the resilience of young refugees with matched population controls in order to conclusively determine if refugee adolescents' resilience is significantly diminished. If resilience predicts psychopathology in refugee adolescents as the literature with nonrefugee young people suggests, $[22,39]$ then targeting and enhancing resilience including its various components may be critical to interventions designed to alleviate psychological symptoms and improve psychosocial well being in young refugees. Future research could longitudinally track the progression of resilience and mental health in young refugees to determine the directionality of this relationship.

Due to the complex relationship between resilience and both sociodemographic characteristics as well as pre- and postmigration factors, any interventions will need to be targeted with sensitivity to these factors. The use of resilience measures that more fully capture not only the personal, but the family and social domains of the resilience construct, can also inform future research. This appears to be especially relevant in studies with refugee populations who mainly originate from collectivist societies where family and the community are paramount to one's well being and identity. Such research could also benefit from exploring the association between resilience and mental health service use which was hampered by the low numbers of service users in this sample but which suggests that service users tend to be lower on resilience. Finally, the present study could be extended to explore the nature of resilience in younger refugee children and examine the changes, if any, in the relationship between resilience and mental health from childhood to adolescence.

\section{Funding}

This study was supported by a grant from the Australian Research Council (Grant no. LP0562492).

\section{Acknowledgments}

The authors wish to thank parents, adolescents, teachers, and the Migrant Resource Centre of South Australia. Our research assistants included Mr. Ben Stewart, Ms. Teresa Puvimanasinghe, Ms. Bev Rundle, and Ms. Lynda Caudle.

\section{References}

[1] Department of Immigration and Citizenship, "Australian Government Department of Immigration and Citizenship Annual Report 2009-2010".

[2] S. L. Lustig, M. Kia-Keating, W. G. Knight et al., "Review of child and adolescent refugee mental health," Journal of the
American Academy of Child and Adolescent Psychiatry, vol. 43, no. 1, pp. 24-36, 2004.

[3] Senate Select Committee on Mental Health, "A national approach to mental health-from crisis to community," Final Report, Commonwealth of Australia, 2006.

[4] R. S. McKelvey, D. L. Sang, L. Baldassar, L. Davies, L. Roberts, and N. Cutler, "The prevalence of psychiatric disorders among Vietnamese children and adolescents," Medical Journal of Australia, vol. 177, no. 8, pp. 413-417, 2002.

[5] J. Krupinski and G. D. Burrows, The Price of Freedom: Young Indochinese Refugees in Australia, Pergamon, Sydney, Australia, 1986.

[6] K. Almqvist and M. Brandell-Forsberg, "Refugee children in sweden: post-traumatic stress disorder in iranian preschool children exposed to organized violence," Child Abuse and Neglect, vol. 21, no. 4, pp. 351-366, 1997.

[7] E. M. Rothe, J. Lewis, H. Castillo-Matos, O. Martinez, R. Busquets, and I. Martinez, "Posttraumatic stress disorder among Cuban children and adolescents after release from a refugee camp," Psychiatric Services, vol. 53, no. 8, pp. 970-976, 2002.

[8] S. Weine, D. F. Becker, T. H. McGlashan, D. Vojvoda, S. Hartman, and J. P. Robbins, "Adolescent survivors of 'Ethnic cleansing' observations on the first year in America," Journal of the American Academy of Child and Adolescent Psychiatry, vol. 34, no. 9, pp. 1153-1159, 1995.

[9] W. H. Sack, G. N. Clarke, and J. Seeley, "Multiple forms of stress in Cambodian adolescent refugees," Child Development, vol. 67, no. 1, pp. 107-116, 1996.

[10] J. D. Kinzie, W. H. Sack, R. H. Angell, G. N. Clarke, and R. Ben, "The psychiatric effects of massive trauma on Cambodian children: I. The children," Journal of the American Academy of Child Psychiatry, vol. 25, no. 3, pp. 370-376, 1986.

[11] D. Servan-Schreiber, B. Le Lin, and B. Birmaher, "Prevalence of posttraumatic stress disorder and major depressive disorder in Tibetan refugee children," Journal of the American Academy of Child and Adolescent Psychiatry, vol. 37, no. 8, pp. 874-879, 1998.

[12] M. Fazel, J. Wheeler, and J. Danesh, "Prevalence of serious mental disorder in 7000 refugees resettled in western countries: a systematic review," The Lancet, vol. 365, no. 9467, pp. 1309-1314, 2005.

[13] R. F. Mollica, C. Poole, L. Son, C. C. Murray, and S. Tor, "Effects of war trauma on Cambodian refugee adolescents" functional health and mental health status," Journal of the American Academy of Child and Adolescent Psychiatry, vol. 36, no. 8, pp. 1098-1106, 1997.

[14] T. Ziaian, H. de Anstiss, G. Antoniou, M. Sawyer, and P. Baghurst, "Depressive symptomatology and service utilisation among refugee children and adolescents living in South Australia," Child and Adolescent Mental Health. In press.

[15] M. Hodes, "Psychologically distressed refugee children in the United Kingdom," Child Psychology and Psychiatry Review, vol. 5, no. 2, pp. 57-68, 2000.

[16] D. Summerfield, "Childhood, war, refugeedom and 'trauma': three core questions for mental health professionals," Transcultural Psychiatry, vol. 37, no. 3, pp. 417-433, 2000.

[17] D. Becker, R. J. Kleber, C. R. Figley, and B. P. R. Gersons, “The deficiency of the concept of posttraumatic stress when dealing with victims of human rights violations," in Beyond Trauma: Cultural and Societal Dynamics, R. J. Kleber, C. R. Figley, and B. P. R. Gersons, Eds., pp. 99-110, Plenum, New York, NY, USA, 1995. 
[18] K. E. Miller and L. M. Rasco, "An ecological framework for addressing the mental health needs of refugee communities," in The Mental Health of Refugees: Ecological Approaches to Healing and Adaptation, K. E. Miller and L. M. Rasco, Eds., pp. 1-64, Lawrence Erlbaum Associates, New Jersey, NJ, USA, 2004.

[19] M. A. Muecke, "New paradigms for refugee health problems," Social Science and Medicine, vol. 35, no. 4, pp. 515-523, 1992.

[20] E. Crawford, M. O. Wright, and A. Masten, "Resilience and spirituality in youth," in The Handbook of Apiritual Development in Childhood and Adolescence, E. C. Roehlkepartain, P. E. King, L. Wagener, and P. L. Benson, Eds., Sage, Thousand Oaks, Calif, USA, 2005.

[21] M. Rutter, "Psychosocial resilience and protective mechanisms," American Journal of Orthopsychiatry, vol. 57, no. 3, pp. 316-331, 1987.

[22] O. Hjemdal, P. A. Vogel, S. Solem, K. Hagen, and T. C. Stiles, "The relationship between resilience and levels of anxiety, depression, and obsessive-compulsive symptoms in adolescents," Clinical Psychology and Psychotherapy, vol. 18, no. 4, pp. 314-321, 2011.

[23] K. M. Connor and J. R. T. Davidson, "Development of a new Resilience scale: the Connor-Davidson Resilience scale (CDRISC)," Depression and Anxiety, vol. 18, no. 2, pp. 76-82, 2003.

[24] K. Almqvist and A. G. Broberg, "Mental health and social adjustment in young refugee children $31 / 2$ years after their arrival in Sweden," Journal of the American Academy of Child and Adolescent Psychiatry, vol. 38, no. 6, pp. 723-730, 1999.

[25] M. Ajdukovic and D. Ajdukovic, "Psychological well-being of refugee children," Child Abuse and Neglect, vol. 17, no. 6, pp. 843-854, 1993.

[26] M. M. Tsoi, G. K. K. Yu, and F. Lieh-Mak, "Vietnamese refugee children in camps in Hong Kong," Social Science and Medicine, vol. 23, no. 11, pp. 1147-1150, 1986.

[27] C. Rousseau, A. Drapeau, and S. Rahimi, "The complexity of trauma response: a 4-year follow-up of adolescent Cambodian refugees," Child Abuse and Neglect, vol. 27, no. 11, pp. 12771290, 2003.

[28] R. Dybdahl, "Children and mothers in war: an outcome study of a psychosocial intervention program," Child Development, vol. 72, no. 4, pp. 1214-1230, 2001.

[29] J. Garbarino and K. Kostelny, "What do we need to know to understand children in war and community violence?" in Minefields in Their Hearts: The Mental Health of Children in War and Communal Violence, A. R. S. Bennett, Ed., pp. 33-51, Yale University, New Haven, Conn, USA, 1996.

[30] M. Ní Raghallaigh, "Religion in the lives of unaccompanied minors: an available and compelling coping resource," British Journal of Social Work, vol. 41, no. 3, pp. 539-556, 2011.

[31] J. H. Goodman, "Coping with trauma and hardship among unaccompanied refugee youths from Sudan," Qualitative Health Research, vol. 14, no. 9, pp. 1177-1196, 2004.

[32] M. Hasanović, S. Srabović, M. Rašidović et al., "Psychosocial assistance to students with posttraumatic stress disorder in primary and secondary schools in post-war Bosnia Herzegovina," Psychiatria Danubina, vol. 21, no. 4, pp. 463-473, 2009.

[33] C. McMichael, S. M. Gifford, and I. Correa-Velez, "Negotiating family, navigating resettlement: family connectedness amongst resettled youth with refugee backgrounds living in Melbourne, Australia," Journal of Youth Studies, vol. 14, no. 2, pp. 179-195, 2011.

[34] A. M. N. Renzaho, J. Green, D. Mellor, and B. Swinburn, "Parenting, family functioning and lifestyle in a new culture: the case of African migrants in Melbourne, Victoria, Australia," Child and Family Social Work, vol. 16, no. 2, pp. 228-240, 2011.

[35] A. M. N. Renzaho, M. McCabe, and W. J. Sainsbury, "Parenting, role reversals and the preservation of cultural values among Arabic speaking migrant families in Melbourne, Australia," International Journal of Intercultural Relations, vol. 35, no. 4, pp. 416-424, 2011.

[36] K. Runkewitz, H. Kirchmann, and B. Strauss, "Anxiety and depression in primary care patients: predictors of symptom severity and developmental correlates," Journal of Psychosomatic Research, vol. 60, no. 5, pp. 445-453, 2006.

[37] L. Campbell-Sills, S. L. Cohan, and M. B. Stein, "Relationship of resilience to personality, coping, and psychiatric symptoms in young adults," Behaviour Research and Therapy, vol. 44, no. 4, pp. 585-599, 2006.

[38] R. A. Burns, K. J. Anstey, and T. D. Windsor, "Subjective wellbeing mediates the effects of resilience and mastery on depression and anxiety in a large community sample of young and middle-aged adults," Australian and New Zealand Journal of Psychiatry, vol. 45, no. 3, pp. 240-248, 2011.

[39] O. Hjemdal, T. Aune, T. Reinfjell, T. C. Stiles, and O. Friborg, "Resilience as a predictor of depressive symptoms: a correlational study with young adolescents," Clinical Child Psychology and Psychiatry, vol. 12, no. 1, pp. 91-104, 2007.

[40] X. N. Yu, J. T. F. Lau, W. W. S. Mak, J. Zhang, and W. W. S. Lui, "Factor structure and psychometric properties of the connor-davidson resilience scale among chinese adolescents," Comprehensive Psychiatry, vol. 52, no. 2, pp. 218-224, 2011.

[41] H. S. Baek, K. U. Lee, E. J. Joo, M. Y. Lee, and K. S. Choi, "Reliability and validity of the Korean version of the ConnorDavidson resilience scale," Psychiatry Investigation, vol. 7, no. 2, pp. 109-115, 2010.

[42] Ö. Karairmak, "Establishing the psychometric qualities of the Connor-Davidson Resilience Scale (CD-RISC) using exploratory and confirmatory factor analysis in a trauma survivor sample," Psychiatry Research, vol. 179, no. 3, pp. 350$356,2010$.

[43] N. Izadinia, M. Amiri, R. G. Jahromi, and S. Hamidi, "A study of relationship between suicidal ideas, depression, anxiety, resiliency, daily stresses and mental health among Tehran university students," in Proceedings of the World Conference on Psychology, Counselling and Guidance (WCPCG'10), vol. 5, pp. 1615-1619, 2010.

[44] S. Ahmad, A. Feder, E. J. Lee et al., "Earthquake impact in a remote south asian population: psychosocial factors and posttraumatic symptoms," Journal of Traumatic Stress, vol. 23, no. 3, pp. 408-412, 2010.

[45] S. Vetter, I. Dulaev, M. Mueller, R. R. Henley, W. T. Gallo, and Z. Kanukova, "Impact of resilience enhancing programs on youth surviving the Beslan school siege," Child and Adolescent Psychiatry and Mental Health, vol. 4, 2010.

[46] D. S. Fincham, L. K. Altes, D. J. Stein, and S. Seedat, "Posttraumatic stress disorder symptoms in adolescents: risk factors versus resilience moderation," Comprehensive Psychiatry, vol. 50, no. 3, pp. 193-199, 2009.

[47] M. Kovacs, Children's Depression Inventory Manual, MultiHealth Systems, North Tonawanda, NY, USA, 1992.

[48] T. F. E. Ahmad and N. Shuriquie, "Psychological sequelae of emotional abuse in institutionalized children," Arab Journal of Psychiatry, vol. 12, no. 2, pp. 36-42, 2001.

[49] E. M. Al-Balhan, “The children's depression inventory as a reliable measure for post-iraqi invasion Kuwaiti youth," Social Behavior and Personality, vol. 34, no. 4, pp. 351-366, 2006. 
[50] H. Liss, V. Phares, and L. Liljequist, "Symptom endorsement differences on the children's depression inventory with children and adolescents on an inpatient unit," Journal of Personality Assessment, vol. 76, no. 3, pp. 396-411, 2001.

[51] C. L. Rivera, G. Bernal, and J. Rosselló, "The Children Depression Inventory (CDI) and the Beck Depression Inventory (BDI): their validity as screening measures for major depression in a group of Puerto Rican adolescents," International Journal of Clinical and Health Psychology, vol. 5, no. 3, pp. 485498, 2005.

[52] R. Goodman, "The extended version of the strengths and difficulties questionnaire as a guide to child psychiatric caseness and consequent burden," Journal of Child Psychology and Psychiatry and Allied Disciplines, vol. 40, no. 5, pp. 791799, 1999.

[53] M. H. Almaqrami and A. Y. Shuwail, "Validity of the selfreport version of the strengths and difficulties questionnaire in Yemen," Saudi Medical Journal, vol. 25, no. 5, pp. 592-601, 2004.

[54] W. Woerner, A. Becker, and A. Rothenberger, "Normative data and scale properties of the German parent SDQ," European Child and Adolescent Psychiatry, vol. 13, supplement 2, pp. ii3ii10, 2004.

[55] W. Woerner, B. Fleitlich-Bilyk, R. Martinussen et al., "The strengths and difficultiesquestionnaire overseas: evaluations and applications of the SDQ beyond Europe," European Child and Adolescent Psychiatry, vol. 13, supplement 2, pp. ii47-ii54, 2004.

[56] N. D. Bilanakis, E. E. Pappas, D. Lecic-Tosevski, and D. B. Alexiou, "Children of war fostered by Greek families for six months: the effect of the programme on children and foster mothers," European Journal of Psychiatry, vol. 13, no. 4, pp. 215-222, 1999.

[57] A. Daud, B. af Klinteberg, and P. A. Rydelius, "Resilience and vulnerability among refugee children of traumatized and nontraumatized parents," Child and Adolescent Psychiatry and Mental Health, vol. 2, 2008.

[58] I. Derluyn and E. Broekaert, "Different perspectives on emotional and behavioural problems in unaccompanied refugee children and adolescents," Ethnicity and Health, vol. 12, no. 2, pp. 141-162, 2007.

[59] M. Fazel and A. Stein, "Mental health of refugee children: comparative study," British Medical Journal, vol. 327, no. 7407, p. 134, 2003.

[60] G. Leavy, K. Hollins, M. King, J. Barnes, C. Papadopoulos, and K. Grayson, "Psychological disorder amongst refugee and migrant schoolchildren in London," Social Psychiatry and Psychiatric Epidemiology, vol. 39, no. 3, pp. 191-195, 2004.

[61] M. G. Sawyer, F. M. Arney, P. A. Baghurst et al., "The mental health of young people in Australia: key findings from the child and adolescent component of the national survey of mental health and well-being," Australian and New Zealand Journal of Psychiatry, vol. 35, no. 6, pp. 806-814, 2001.

[62] M. G. Sawyer, R. J. Kosky, B. W. Graetz, F. Arney, S. R. Zubrick, and P. Baghurst, "The national survey of mental health and wellbeing: the child and adolescent component," Australian and New Zealand Journal of Psychiatry, vol. 34, no. 2, pp. 214220, 2000.

[63] T. Ziaian, H. de Anstiss, G. Antoniou, P. Baghurst, and M. Sawyer, "Emotional and behavioural problems among refugee children and adolescents living in South Australia," Australian Psychologist. In press.

[64] C. Mels, I. Derluyn, E. Broekaert, and Y. Rosseel, "The psychological impact of forced displacement and related risk factors on Eastern Congolese adolescents affected by war," Journal of Child Psychology and Psychiatry and Allied Disciplines, vol. 51, no. 10, pp. 1096-1104, 2010.

[65] A. Roy, M. Sarchiapone, and V. Carli, "Low resilience in suicide attempters," Archives of Suicide Research, vol. 11, no. 3, pp. 265-269, 2007. 


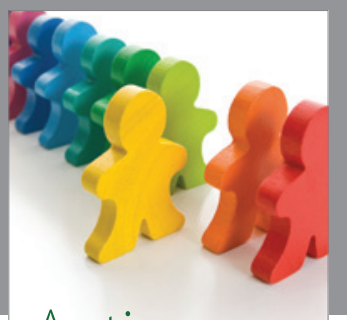

Autism

Research and Treatment
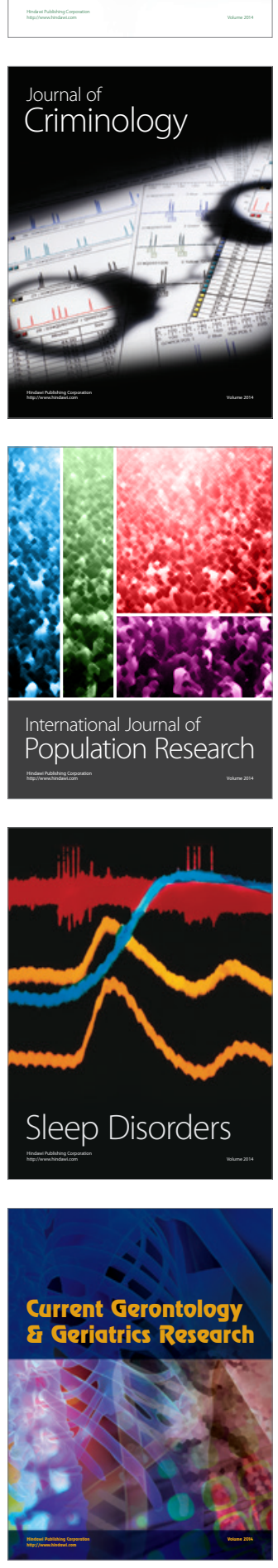
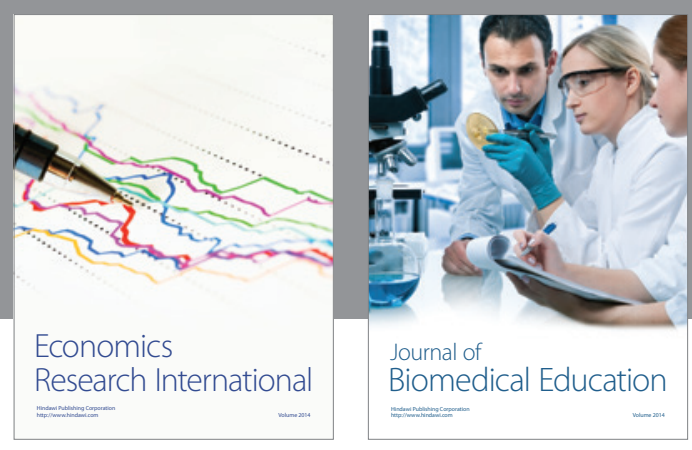

Journal of

Biomedical Education

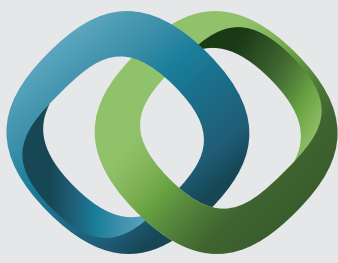

\section{Hindawi}

Submit your manuscripts at

http://www.hindawi.com
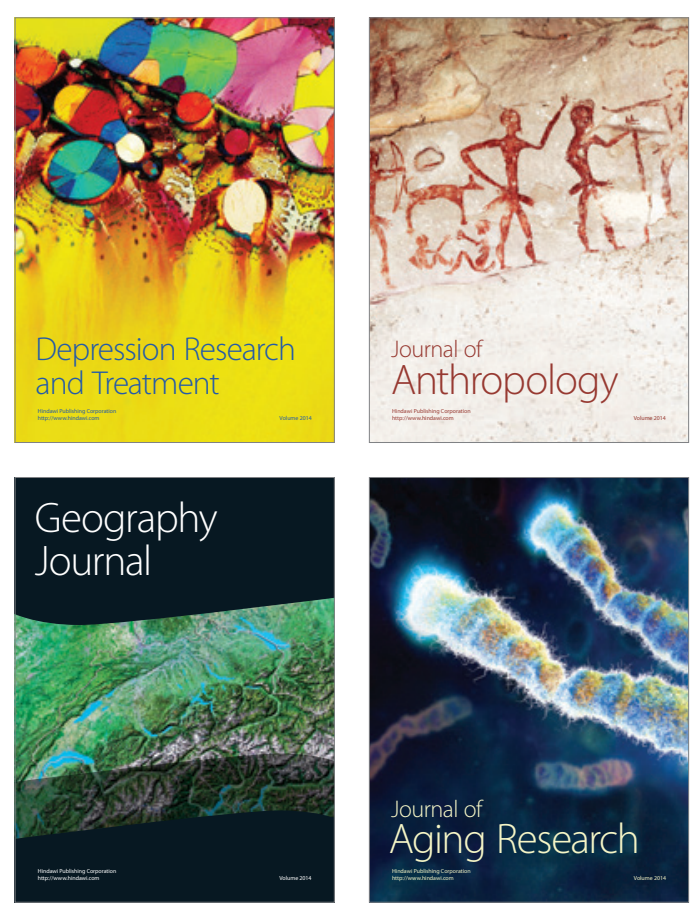

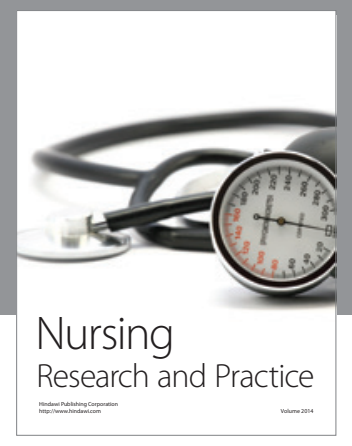

Nursing

Research and Practice

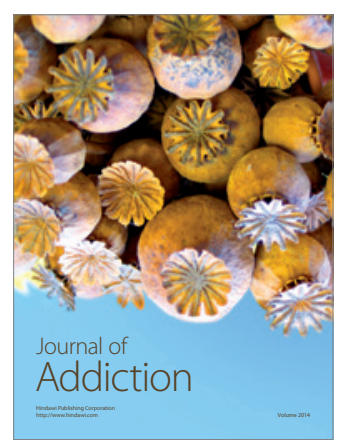

Child Development

Research

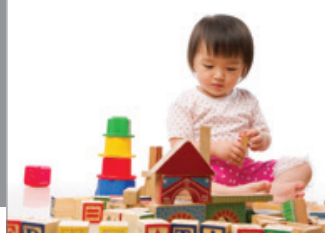

迥
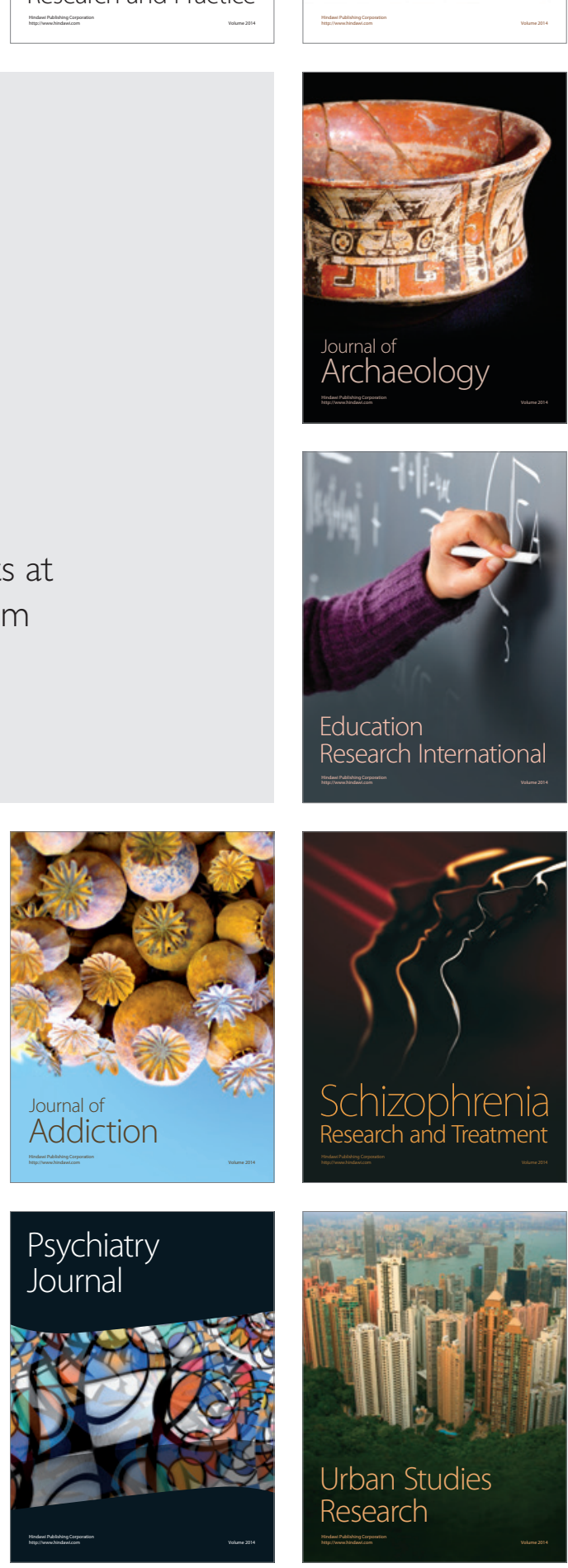